\title{
State Policies Targeting Junk Food in Schools: Racial/Ethnic Differences in the Effect of Policy Change on Soda Consumption
}

\author{
Daniel R. Taber, PhD, MPH, June Stevens, PhD, MS, Kelly R. Evenson, PhD, Dianne S. \\ Ward, EdD, MS, Charles Poole, ScD, MPH, Matthew L. Maciejewski, PhD, David M. Murray, \\ PhD, and Ross C. Brownson, PhD \\ Daniel R. Taber, Kelly R. Evenson, and Charles Poole are with the Department of Epidemiology, \\ Gillings School of Global Public Health, University of North Carolina at Chapel Hill. June Stevens \\ and Dianne S. Ward are with the Department of Nutrition, Gillings School of Global Public Health, \\ University of North Carolina at Chapel Hill. Matthew L. Maciejewski is with the Center for Health \\ Services Research in Primary Care, Durham Veterans Affairs Medical Center, Durham, NC. \\ David M. Murray is with the Division of Epidemiology, College of Public Health, Ohio State \\ University, Columbus. Ross C. Brownson is with the Prevention Research Center, George \\ Warren Brown School of Social Work, Washington University, St. Louis, MO
}

\section{Abstract}

Objectives-We estimated the association between state policy changes and adolescent soda consumption and body mass index (BMI) percentile, overall and by race/ethnicity.

Methods-We obtained data on whether states required or recommended that schools prohibit junk food in vending machines, snack bars, concession stands, and parties from the 2000 and 2006 School Health Policies and Programs Study. We used linear mixed models to estimate the association between 2000-2006 policy changes and 2007 soda consumption and BMI percentile, as reported by 90730 students in 33 states and the District of Columbia in the Youth Risk Behavior Survey, and to test for racial/ethnic differences in the associations.

Results-Policy changes targeting concession stands were associated with 0.09 fewer servings of soda per day among students (95\% confidence interval $[\mathrm{CI}]=-0.17,-0.01)$; the association was more pronounced among non-Hispanic Blacks ( 0.19 fewer servings per day). Policy changes targeting parties were associated with 0.07 fewer servings per day $(95 \% \mathrm{CI}=-0.13,0.00)$. Policy changes were not associated with BMI percentile in any group.

Conclusions-State policies targeting junk food in schools may reduce racial/ethnic disparities in adolescent soda consumption, but their impact appears to be too weak to reduce adolescent BMI percentile.

Obesity among adolescents is associated with type 2 diabetes, hypertension, depressive symptoms, and other adverse outcomes. ${ }^{1}$ It became one of the primary public health concerns in the United States in recent decades as the prevalence escalated from 5\% in the

\footnotetext{
Correspondence should be sent to Daniel R. Taber, PhD, MPH, Health Policy Center, Institute for Health Research and Policy (MC 275), University of Illinois at Chicago, 1747 W. Roosevelt Rd, Chicago, IL 60608 (dtaber@uic.edu).

Contributors

D. R. Taber conceptualized and designed the study, conducted the analyses, and led the writing. J. Stevens supervised the study as doctoral dissertation chair, contributed to the study conceptualization and design, and assisted with the interpretation of results. K. R. Evenson, D. S. Ward, and R. C. Brownson contributed to the study conceptualization and interpretation of results. C. Poole, M. L. Maciejewski, and D. M. Murray contributed to the study design and statistical analyses. All authors participated in revising and editing the article.

Human Participant Protection

This study was approved by the institutional review board of the University of North Carolina, Chapel Hill.
} 
years 1976 to 1980 to $18 \%$ in the period 2003 to $2006 .^{2}$ Soda is widely considered to be a contributor to the increase in obesity because it has been associated with excess energy intake and weight gain in several cross-sectional and prospective cohort studies. ${ }^{3,4}$ It became a larger source of energy intake among adolescents during the same period that obesity prevalence increased. ${ }^{5-7}$ Data from the 2005-2006 National Health and Nutrition Examination Survey indicated that soda accounted for 33\% of the gram weight of beverages consumed by children (2-18 years), more than any other beverage. ${ }^{8}$

There has been a movement on several governing levels to remove soda and other foods and beverages of high caloric density from schools. ${ }^{9-13}$ Foods and beverages sold outside of federal school meal programs are not required to meet federal nutrition standards. Reviews by Larson and Story ${ }^{14}$ and Story et al. ${ }^{12}$ demonstrated that such "competitive foods" are widely available in schools, have poor nutritional content, and have been associated with poor diet among youths. As such evidence has grown, policies to improve the nutritional content of school foods and beverages have become more prevalent. ${ }^{15}$ Much of the focus has been on the district level, particularly through the Child Nutrition and Women, Infants, and Children Reauthorization Act of 2004. ${ }^{16}$ This legislation mandated that by the start of the 2006-2007 school year, local education agencies participating in federal school meal and child nutrition programs must establish nutrition guidelines for foods and beverages sold outside of the school meal program as part of a wellness policy to address childhood obesity.

On the state level, policymakers introduced 213 bills and 25 resolutions targeting nutrition standards and vending machines in schools between 2003 and 2005. ${ }^{17}$ These included restricting access to vending machines and regulating the marketing of foods and beverages with high-caloric density and low-nutrient density. Kubik et al. found that state, not district, policies were associated with school practices regarding junk food availability, ${ }^{18}$ but little research has evaluated the effect of state policies on students' soda consumption. Evaluations of state policy interventions in Texas ${ }^{19}$ and California ${ }^{20}$ generally found improvements in school food environments and students' dietary intake after the policy change, but neither study used another state as a control. It is therefore unknown whether the changes they reported were attributable to policy change or secular trends. To our knowledge, no study has compared food or beverage intake, or weight status, in states that changed their policies and in those that did not.

Some authors have maintained that schools supply less than $15 \%$ of the calories students get from sugar-sweetened beverages ${ }^{7}$ and that students can easily compensate for policy changes by relying on other sources. ${ }^{21,22}$ Racial/ethnic minorities, in particular, have access to fast-food outlets, convenience stores, and other sources of energy-dense foods surrounding schools and in the community, ${ }^{22,23}$ which may negate the effect of policy changes. Disparities in policy effectiveness have not been explored, however, because existing policy research has generally focused on ethnic majority populations. ${ }^{24}$ Comparing policy effectiveness across racial/ethnic groups is important given that the prevalence of obesity is higher among many minority populations than among non-Hispanic Whites. ${ }^{25}$

Our objective was to estimate (1) the associations between state policy changes targeting junk food in schools and soda consumption and percentile of body mass index (BMI; defined as weight in kilograms divided by height in meters squared) among adolescents overall and (2) the difference in these associations across racial/ethnic groups. We hypothesized that soda consumption would be lower among adolescents in states that changed school policies to restrict access to junk food than among adolescents in states that did not, and that this effect would be seen across all racial/ethnic groups in spite of the disadvantages that some face in the built environment outside of school. 


\section{METHODS}

We combined student- and state-level data from multiple studies conducted by the Centers for Disease Control and Prevention to estimate the association between state policy changes that took place between 2000 and 2006 and student outcomes measured in 2007.

\section{Measures}

State policies-We obtained data on state policies regarding junk food in schools from the 2000 and 2006 School Health Policies and Programs Study (SHPPS), a national survey that collected data on school health policies and practices at the state, district, school, and classroom levels. ${ }^{26}$ SHPPS has been conducted every 6 years since 1994. All states and the District of Columbia participated in SHPPS in both 2000 and 2006.

State policies were collected through computer-assisted telephone interviews or selfadministered mailed questionnaires. The data in this study were provided by personnel who were identified by the state education agency or department of health as being most knowledgeable about food service policies. The official title of survey respondents varied by state, but it was normally the director of school nutrition, director of child nutrition, or a comparable position.

In both 2000 and 2006, respondents were asked if the state required or recommended that schools be prohibited from offering junk foods in several different settings around school. Our analyses focused specifically on policies regarding vending machines; school stores, canteens, and snack bars; student parties; and concession stands. "Junk food" was defined in the 2000 survey as "foods that provide calories primarily through fats or added sugars and have minimal amounts of vitamins and minerals." $27 \mathrm{a(p8)}$ The definition was slightly modified in 2006 ("foods or beverages that have low nutrient density, that is they provide calories primarily through fats or added sugars and have minimal amounts of vitamins and minerals"). ${ }^{27 \mathrm{~b}(\mathrm{p} 9)}$ Participants could answer "require," "recommend," or "neither" for each setting.

Student measures-We obtained student data from the 2007 state Youth Risk Behavior Survey (YRBS). YRBS is a biennial survey of 9th- to 12th-grade students, administered on the national, state, and local levels. Students were sampled by a 2-stage cluster sampling design, and data were weighted according to school and student response rates to produce estimates that were representative of the state jurisdiction. ${ }^{28}$ Data were weighted only in states that provided appropriate documentation and had an overall response rate of $60 \%$ or higher. We excluded states from our study that did not meet these criteria $(n=5)$, did not participate in the 2007 YRBS $(n=6)$, did not measure soda consumption in $2007(n=1)$, did not provide all relevant policy data $(n=2)$, chose to not provide individual student data $(n=1)$, or determined that their data were not representative $(n=2)$. A total of 90730 students from 33 states (AR, AZ, DE, FL, GA, HI, ID, IL, IN, IA, KS, KY, ME, MA, MS, MO, MI, NV, NH, NM, NY, NC, ND, OH, RI, SC, TN, TX, UT, VT, WV, WI, WY) and the District of Columbia met inclusion criteria.

Our outcomes of interest were total servings of soda per day and BMI percentile. Through use of a written questionnaire administered in class, students were asked, "During the past 7 days, how many times did you drink a can, bottle, or glass of soda or pop, such as Coke, Pepsi, or Sprite?" The question did not differentiate between soda consumed within and outside of school. Students also reported their height and weight, which was used to calculate BMI percentile. BMI percentile accounts for developmental differences between boys and girls of different ages by measuring each student's BMI relative to a reference population composed of children of the same age and gender in the United States. ${ }^{29}$ Brener 
et al., in their study of the validity of self-reported height and weight data in the YRBS, found that students overreported their height by an average of 2.7 inches and underreported their weight by an average of 3.5 pounds, producing a correlation between measured and self-reported BMI of 0.89 .30

Students reported their gender, race (American Indian or Alaska Native, Asian, Black or African American, Native Hawaiian or other Pacific Islander, White), and ethnicity (Hispanic/Latino or non-Hispanic) on the questionnaire. Race and ethnicity were combined to create a 4-category measure: non-Hispanic White, non-Hispanic Black, Hispanic, and non-Hispanic other.

State covariates-State median income, ${ }^{31}$ political party of the state legislature, ${ }^{31,32}$ and obesity prevalence among adults ${ }^{31}$ have been associated with legislative activity targeting obesity. These variables can confound the effect of soda policy change through their association with other types of policies (e.g., physical education requirements). We obtained income data from the US Census, ${ }^{33}$ the prevalence of obesity among adults from the state Behavioral Risk Factor Surveillance System, ${ }^{34}$ and state legislature political party after the 2000 election from the National Conference of State Legislatures. ${ }^{35}$

\section{Statistical Analysis}

Our primary analysis estimated the association between policy changes that took place between 2000 and 2006 and servings of soda per day in 2007. We based analyses on the general linear mixed model using a maximum likelihood estimator with robust standard errors. We adapted the notation for the model from Murray, ${ }^{36}$ as follows:

$$
\text { Soda }_{i: j}=\beta_{0}+\beta_{1}(2006 \text { policy })+\beta_{x} X+S_{j}+\epsilon_{i: j}
$$

Soda $_{\mathrm{i}: \mathrm{j}}$ represents servings of soda per day (using an identity link) for the ith individual nested within state $\mathrm{j}$. Mixed models account for state clustering by estimating an overall intercept, $\beta_{0}$, as well as a random intercept $\left(S_{j}\right)$ by state,; $N\left(0, \sigma_{s}^{2}\right)$. X represents all studentand state-level covariates. We restricted models to states that reported neither "recommend" nor "require" for the policy of interest in 2000; the coefficients for 2006 policy therefore represented the effect of policy changes that took place between 2000 and 2006. We analyzed changes in policies targeting different settings (e.g., vending machines, snack bars) in distinct models. Whenever possible, we compared states that reported "require" with states that reported "neither" in 2006, as well as states that reported "require" or "recommend" with states that reported "neither" in 2006.

We used a directed acyclic graph (Appendix 1, available as a supplement to the online version of this article at http://www.ajph.org) to select covariates for our models. Directed acyclic graphs are causal diagrams used to identify adjustment variables and avoid biases caused by overadjustment. ${ }^{37-39}$ Using Appendix 1 and systematic graphical criteria, we identified the following variables as the minimal set that was sufficient to control confounding: student gender and race/ethnicity, state log median income (continuous), state adult obesity prevalence (continuous), and whether both houses of the state legislature were controlled by the Democratic party (binary).

After estimating the overall association between policy change and soda consumption for each setting, we tested for differences in the association across racial/ethnic groups. We repeated the model after adding an interaction term between 2006 policy and each racial/ ethnic group except non-Hispanic Whites. We used a likelihood ratio test to determine 
whether the overall interaction between race/ethnicity and policy was statistically significant $(\alpha=0.05, d f=3)$.

After modeling the associations between policy measures and soda consumption, we repeated each model with BMI percentile as the outcome. We conducted all analyses with Mplus Version 5.21 to incorporate the YRBS sampling weights. ${ }^{40}$

\section{RESULTS}

Weighted descriptive statistics are provided in Table 1. Overall, the sample was $62 \%$ nonHispanic White, 18\% non-Hispanic Black, 15\% Hispanic, and 5\% non-Hispanic other. The racial/ethnic groups had similar distributions of age and gender. The distribution of soda consumption was positively skewed in all racial/ethnic groups, with a median of 0.7 servings per day and a mean of 1.0. The mean number of servings of soda per day was highest among non-Hispanic Blacks. The prevalence of obesity ranged from $11.4 \%$ among non-Hispanic Whites to $16.3 \%$ among Hispanics.

\section{School Policy Changes Between 2000 and 2006}

For each of the settings that we examined, at least 28 of the 33 participating states and the District of Columbia reported that they neither recommended nor required that schools be prohibited from offering junk food in 2000. A summary of 2000-2006 policy changes in these states can be found in Appendix 2 (available as a supplement to the online version of this article at http://www.ajph.org), which displays the distribution of 2006 policies among states that reported "neither" in 2000. Because only 1 state changed from "neither" to "require" for policies targeting concession stands and parties, we compared only states that reported "require" or "recommend" (combined) with states that reported "neither" for these settings.

\section{State Policy Changes and Soda Consumption}

Only policy changes targeting concession stands and parties were associated with selfreported soda consumption (Table 2). The mean number of servings per day was 0.09 lower (95\% confidence interval $[\mathrm{CI}]=-0.17,-0.01$ ) among adolescents in states that re-quired or recommended that junk food not be allowed in concession stands, relative to adolescents in states that did not. The effect size for parties was slightly weaker (difference $=-0.07 ; 95 \%$ $\mathrm{CI}=-0.13,0.00$ ). For snack bars and vending machines, there was no association between policy changes and soda consumption regardless of whether we compared states that reported "require" with states that reported "neither" or states that reported "require" or "recommend" with states that reported "neither."

Although most associations were null in the sample overall, they differed by race/ethnicity for each setting $(P<.001)$, particularly between non-Hispanic Whites and non-Hispanic Blacks (Table 3). Across all settings, there was no association among non-Hispanic Whites but a negative association among non-Hispanic Blacks. The coefficients for concession stands among non-Hispanic Blacks (difference $=-0.19$ ) suggests that adolescents whose state changed their school policies consumed approximately 1.33 fewer servings per week ( 7 days $\times 0.19$ ) compared with those who resided in states that did not change their policies. The associations in other settings were slightly weaker. Across settings, the difference between non-Hispanic Whites and non-Hispanic Blacks in the association between policy change and soda consumption was similar to the difference in mean soda consumption between the 2 groups (Table 1). Among Hispanics, the estimated associations were slightly weaker and less precise than among non-Hispanic Blacks. 


\section{State Policy Changes and Body Mass Index Percentile}

Table 4 displays the association between policy change and students' BMI percentile in 2007, by race/ethnicity. Although the overall interaction between race/ethnicity and policy was statistically significant for each setting except school parties, this interaction was largely driven by unusually large associations among adolescents in the "non-Hispanic other" group. BMI percentile was not associated with any policy change in any other racial/ethnic group or in the overall sample. We explored the association among "non-Hispanic other" adolescents in more detail and found evidence that it may be confounded by the distribution of individual racial/ethnic categories (American Indian/Alaska Native, Asian, Native Hawaiian/Pacific Islander, and multiple/non-Hispanic). Specifically, states that made policy changes had a higher proportion of American Indians/Alaska Natives and lower proportion of Asians than did states that made no changes, and the mean BMI percentile among American Indians/Alaska Natives was almost 10 units higher than it was among Asians (64.3 and 54.7, respectively).

\section{DISCUSSION}

To our knowledge, this was the first study to estimate the association between state policy changes targeting junk food in schools and adolescent soda consumption or BMI percentile in a national sample. Interestingly, we found that the association was generally restricted to non-Hispanic Blacks, among whom consumption of sugar-sweetened beverages has increased in recent years. ${ }^{7}$ The differences in effect sizes between non-Hispanic Blacks and non-Hispanic Whites suggest that state policies targeting junk food in schools may be a means to reduce disparities in soda consumption between these groups.

These results extend 2 earlier sets of crosssectional studies: those that found school policies and practices to be associated with sugar-sweetened beverage exposure or consumption among students ${ }^{41,42}$ and those that reported improvements in students' dietary intake following state policy change. ${ }^{19,20}$ This study builds on previous studies by using multiple years of policy data in 33 states and controlling for state variables that may have motivated policy change. These study features provide additional evidence that policy changes may lead to lower soda consumption, although causality cannot be inferred because of the observational design.

Our study also highlighted concession stands and parties as areas where states and schools may influence student soda consumption. In a study of adolescent alcohol consumption, Ellickson et al. examined the effect of advertising in several settings and found that concession stand advertising was associated with alcohol consumption among ninth-grade students, ${ }^{43}$ but concession stands and parties have generally been ignored in previous obesity policy research. Concession stands may include events that lie within a school's jurisdiction even though they take place outside of the school day (e.g., football games). Thus, our findings identify a means by which schools may influence adolescent soda consumption even if consumption primarily takes place outside of school hours. Additional research is needed to explore which sources students primarily rely on for soda and other energy-dense foods and beverages.

Despite the association between policy change and soda consumption among non-Hispanic Blacks, there was no association between policy change and BMI percentile. Cawley et al. reported similar null findings when studying the effect of state policies regarding physical education requirements. ${ }^{44}$ State requirement policies were associated with minutes of activity during physical education, but there was no association between time spent active during physical education and obesity among boys or girls. The failure of policies to affect BMI or obesity, even if they change individual behaviors, may be an indication that the 
effect on behaviors is too small. The largest effect size in any racial/ethnic group in our study was only 0.19 servings per day. The serving sizes were not standardized, but if a serving represented a 20 -ounce bottle, 0.19 servings would represent less than 50 kilocalories. In several studies, estimates of the energy gap that accounts for weight gain in the United States have ranged from 100 to 250 kilocalories per day. ${ }^{45-47}$ An effect size of 0.19 servings may therefore be insufficient to change BMI percentile.

Furthermore, students may be compensating for changes in soda consumption by consuming different kinds of junk foods or sugar-sweetened beverages (e.g., sports drinks). Cullen et al. reported that after policies restricted student access to certain junk foods from snack bars and vending machines, consumption of the targeted foods decreased, but consumption of other junk foods increased, and students obtained junk foods from different sources (e.g., home). ${ }^{19,48}$ This finding led the authors to conclude that all food environments must be targeted if policies are to have an impact. Hispanics, for example, are more likely to attend schools surrounded by convenience stores, restaurants, and other food outlets, ${ }^{22,23}$ allowing more opportunities to compensate for within-school policy changes.

These challenges have led several researchers and policymakers to call for comprehensive policy change at the federal, state, and local levels. ${ }^{9,12,49-51}$ District wellness policies were just starting to be implemented when the student data used in this study were collected, and the comprehensive effect of state and district policies may be more effective in reducing BMI and obesity. The Alliance School Beverage Guidelines, which were scheduled to be fully implemented by the 2009-2010 school year, were also designed to improve the nutritional content of school beverages. ${ }^{52}$ Future research should explore the cumulative effect of policy changes on different governing levels and continue to explore whether the effect of comprehensive change can reduce disparities in both soda consumption and obesity.

The large association between policy change and BMI percentile among "non-Hispanic other" adolescents was likely due to differences between policy categories in the racial/ ethnic distribution. Nonetheless, we found no evidence that policy changes had a beneficial effect within this group, which is a concern given the high prevalence of obesity and type 2 diabetes among American Indian and Alaska Native youths in particular. ${ }^{53}$ Future research should continue to explore racial/ethnic differences in policy effects in an effort to identify policies that are more effective in this population.

\section{Limitations}

Several limitations should be considered when interpreting these findings. Measurement error due to self-report may have biased our estimates because adolescents commonly overreport height ${ }^{30}$ and underreport weight ${ }^{30}$ and dietary intake. ${ }^{54}$ The accuracy of selfreported height and weight may also vary by race/ethnicity. ${ }^{55}$ The survey did not measure serving size, nor did it distinguish between diet and regular soda; both limitations precluded us from estimating differences in energy intake between policy groups. We also could not examine within-student change in soda consumption or BMI percentile because individual students were not followed over time nor could we measure exactly when policy changes took place. If policy changes occurred in 2006, there may not have been sufficient time for them to affect BMI percentile. State policies may also vary in the wording of the policies (e.g., different states may restrict different types of beverages), and no study has evaluated the validity of SHPPS data by having an independent investigator compare surveys with policy documentation. Finally, survey weights were designed to represent individual states, but the analysis was restricted to 33 states and the District of Columbia, and thus results cannot be generalized to the United States as a whole. 


\section{Conclusions}

This study provides evidence that changes in state policies restricting junk food in schools are associated with reduced soda consumption among adolescents, particularly non-Hispanic Blacks. The effect of individual policies, however, may be too weak to reduce adolescent obesity. Future research should evaluate the impact of comprehensive policy change, inside and outside of schools, on adolescent obesity.

\section{Supplementary Material}

Refer to Web version on PubMed Central for supplementary material.

\section{Acknowledgments}

This study was supported by funds from the National Heart, Lung, and Blood Institute (R21 HL097374) and the Caroline H. and Thomas S. Royster Fellowship of the University of North Carolina, Chapel Hill.

We thank the Centers for Disease Control and Prevention and the state education agencies and health departments that generously shared their Youth Risk Behavior Survey data.

\section{References}

1. Must A, Strauss RS. Risks and consequences of childhood and adolescent obesity. Int J Obes Relat Metab Disord. 1999; 23(suppl 2):S2-S11. [PubMed: 10340798]

2. Ogden CL, Carroll MD, Flegal KM. High body mass index for age among US children and adolescents, 2003-2006. JAMA. 2008; 299(20):2401-2405. [PubMed: 18505949]

3. Malik VS, Schulze MB, Hu FB. Intake of sugar-sweetened beverages and weight gain: a systematic review. Am J Clin Nutr. 2006; 84(2):274-288. [PubMed: 16895873]

4. Vartanian LR, Schwartz MB, Brownell KD. Effects of soft drink consumption on nutrition and health: a systematic review and meta-analysis. Am J Public Health. 2007; 97(4):667-675. [PubMed: 17329656]

5. Nielsen SJ, Popkin BM. Changes in beverage intake between 1977 and 2001. Am J Prev Med. 2004; 27(3):205-210. [PubMed: 15450632]

6. Nielsen SJ, Siega-Riz AM, Popkin BM. Trends in energy intake in US between 1977 and 1996: similar shifts seen across age groups. obesity Res. 2002; 10(5):370-378.

7. Wang YC, Bleich SN, Gortmaker SL. Increasing caloric contribution from sugar-sweetened beverages and 100\% fruit juices among US children and adolescents, 1988-2004. Pediatrics. 2008; 121(6):e1604-e1614. [PubMed: 18519465]

8. Dietary Guidelines for Americans, 2010. US Dept of Health and Human Services, US Dept of Agriculture; Washington, DC: 2010.

9. Hayne CL, Moran PA, Ford MM. Regulating environments to reduce obesity. J Public Health Policy. 2004; 25(3-4):391-407. [PubMed: 15683074]

10. Institute of Medicine. Nutrition Standards for Foods in Schools: Leading the Way Toward Healthier Youth. National Academies Press; Washington, DC: 2007.

11. Katz DL, O'Connell M, Yeh MC, et al. Public health strategies for preventing and controlling overweight and obesity in school and worksite settings: a report on recommendations of the Task Force on Community Preventive Services. MMWR Recomm Rep. 2005; 54(RR-10):1-12. [PubMed: 16261131]

12. Story M, Nanney MS, Schwartz MB. Schools and obesity prevention: creating school environments and policies to promote healthy eating and physical activity. Milbank Q. 2009; 87(1):71-100. [PubMed: 19298416]

13. American Academy of Pediatrics. Soft drinks in schools. Pediatrics. 2004; 113(1 pt 1):152-154. [PubMed: 14702469]

14. Larson N, Story M. Are "competitive foods" sold at school making our children fat? Health Aff (Millwood). 2010; 29(3):430-435. [PubMed: 20194984] 
15. Chriqui, J.; Schneider, L.; Chaloupka, F., et al. School Years 2006-07, 2007-08 and 2008-09. Vol. 2. Bridging the Gap, Healthy Policy Center, Institute for Health Research and Policy, University of Illinois at Chicago; Chicago, IL: 2010. School District Wellness Policies: Evaluating Progress and Potential for Improving Children's Health Three Years After the Federal Mandate.

16. Child Nutrition and WIC Reauthorization Act of 2004, Pub L No. 108-265, 118 Stat 780.

17. Boehmer TK, Brownson RC, Haire-Joshu D, Dreisinger ML. Patterns of childhood obesity prevention legislation in the United States. Prev Chronic Dis. 2007; 4(3):A56. [PubMed: 17572960]

18. Kubik MY, Wall M, Shen L, et al. State but not district nutrition policies are associated with less junk food in vending machines and school stores in US public schools. J Am Diet Assoc. 2010; 110(7):1043-1048. [PubMed: 20630161]

19. Cullen KW, Watson K, Zakeri I. Improvements in middle school student dietary intake after implementation of the Texas Public School Nutrition Policy. Am J Public Health. 2008; 98(1): 111-117. [PubMed: 18048778]

20. Woodward-Lopez G, Gosliner W, Samuels SE, Craypo L, Kao J, Crawford PB. Lessons learned from evaluations of California's statewide school nutrition standards. Am J Public Health. 2010; 100(11):2137-2145. [PubMed: 20864696]

21. Finkelstein E, French S, Variyam JN, Haines PS. Pros and cons of proposed interventions to promote healthy eating. Am J Prev Med. 2004; 27(3 suppl):163-171. [PubMed: 15450627]

22. Sturm R. Disparities in the food environment surrounding US middle and high schools. Public Health. 2008; 122(7):681-690. [PubMed: 18207475]

23. Lovasi GS, Hutson MA, Guerra M, Neckerman KM. Built environments and obesity in disadvantaged populations. Epidemiol Rev. 2009; 31:7-20. [PubMed: 19589839]

24. Brownson RC, Haire-Joshu D, Luke DA. Shaping the context of health: a review of environmental and policy approaches in the prevention of chronic diseases. Annu Rev Public Health. 2006; 27:341-370. [PubMed: 16533121]

25. Wang Y, Beydoun MA. The obesity epidemic in the United States--gender, age, socioeconomic, racial/ethnic, and geographic characteristics: a systematic review and meta-regression analysis. Epidemiol Rev. 2007; 29:6-28. [PubMed: 17510091]

26. Kyle TM, Brener ND, Kann L, et al. Methods: School Health Policies and Programs Study 2006. J Sch Health. 2007; 77(8):398-407. [PubMed: 17908100]

27a. Centers for Disease Control and Prevention. [Accessed February 7, 2011] School Health Policies and Programs Study: Food Service State Questionnaire. 2000. Available at: http://www.cdc.gov/healthyyouth/shpps/2000/questionnaire/pdf/foodsers2000questionnaire.pdf

27b. Centers for Disease Control and Prevention. [Accessed February 7, 2011] 2006 School Health Policies and Programs Study: Food Services State Questionnaire. Available at: http://www.cdc.gov/healthyyouth/shpps/2006/questionnaires/pdf/foodsers2006questionnaire.pdf

28. Brener ND, Kann L, Kinchen SA, et al. Methodology of the youth risk behavior surveillance system. MMWR Recomm Rep. 2004; 53(RR-12):1-13. [PubMed: 15385915]

29. Kuczmarski RJ, Ogden CL, Grummer-Strawn LM, et al. CDC growth charts: United States. Adv Data. 2000; (314):1-27. [PubMed: 11183293]

30. Brener ND, McManus T, Galuska DA, Lowry R, Wechsler H. Reliability and validity of selfreported height and weight among high school students. J Adolesc Health. 2003; 32(4):281-287. [PubMed: 12667732]

31. Cawley J, Liu F. Correlates of state legislative action to prevent childhood obesity. Obesity (Silver Spring). 2008; 16(1):162-167. [PubMed: 18223629]

32. Boehmer TK, Luke DA, Haire-Joshu DL, Bates HS, Brownson RC. Preventing childhood obesity through state policy. predictors of bill enactment. Am J Prev Med. 2008; 34(4):333-340. [PubMed: 18374247]

33. US Census Bureau. [Accessed February 7, 2011] American Community Survey. Available at: http://www.census.gov

34. Centers for Disease Control and Prevention. Available at: http://www.cdc.gov/brfss. [Accessed February 7, 2011] Behavioral Risk Factor Surveillance System. http://www.cdc.gov/brfsshttp:// www.cdc.gov/brfss 
35. [Accessed February 7, 2011] National Conference of State Legislatures Web site. Available at: http://www.ncsl.org

36. Murray, D. Design and Analysis of Group-Randomized Trials. Oxford University Press; New York, NY: 1998.

37. Greenland S, Pearl J, Robins JM. Causal diagrams for epidemiologic research. Epidemiology. 1999; 10(1):37-48. [PubMed: 9888278]

38. Pearl J. Causal diagrams for empirical research. Biometrika. 1995; 82(4):669-688.

39. Joffe M, Mindell J. Complex causal process diagrams for analyzing the health impacts of policy interventions. Am J Public Health. 2006; 96(3):473-479. [PubMed: 16449586]

40. Muthen, LK.; Muthen, BO. MPlus User's Guide. 5th ed.. Muthen \& Muthen; Los Angeles, CA: 1998-2007.

41. Briefel RR, Crepinsek MK, Cabili C, Wilson A, Gleason PM. School food environments and practices affect dietary behaviors of US public school children. J Am Diet Assoc. 2009; 109(2 suppl):S91-S107. [PubMed: 19166677]

42. Johnson DB, Bruemmer B, Lund AE, Evens CC, Mar CM. Impact of school district sugarsweetened beverage policies on student beverage exposure and consumption in middle schools. $\mathrm{J}$ Adolesc Health. 2009; 45(3 suppl):S30-S37. [PubMed: 19699434]

43. Ellickson PL, Collins RL, Hambarsoomians K, McCaffrey DF. Does alcohol advertising promote adolescent drinking? Results from a longitudinal assessment. Addiction. 2005; 100(2):235-246. [PubMed: 15679753]

44. Cawley J, Meyerhoefer C, Newhouse D. The impact of state physical education requirements on youth physical activity and overweight. Health Econ. 2007; 16(12):1287-1301. [PubMed: 17328052]

45. Hill JO, Wyatt HR, Reed GW, Peters JC. Obesity and the environment: where do we go from here? Science. 2003; 299(5608):853-855. [PubMed: 12574618]

46. Bouchard C. The magnitude of the energy imbalance in obesity is generally underestimated. Int $\mathbf{J}$ Obes (Lond). 2008; 32(6):879-880. [PubMed: 18197179]

47. Wang YC, Gortmaker SL, Sobol AM, Kuntz KM. Estimating the energy gap among US children: a counterfactual approach. Pediatrics. 2006; 118(6):e1721-e1733. [PubMed: 17142497]

48. Cullen KW, Watson K, Zakeri I, Ralston K. Exploring changes in middle-school student lunch consumption after local school food service policy modifications. Public Health Nutr. 2006; 9(6): 814-820. [PubMed: 16925889]

49. Dietz WH, Bland MG, Gortmaker SL, Molloy M, Schmid TL. Policy tools for the childhood obesity epidemic. J Law Med Ethics. 2002; 30(3 suppl):83-87. [PubMed: 12508508]

50. Harkin T. Preventing childhood obesity: the power of policy and political will. Am J Prev Med. 2007; 33(4 suppl):S165-S166. [PubMed: 17884561]

51. Murkowski L. Preventing obesity in children: the time is right for policy action. Am J Prev Med. 2007; 33(4 suppl):S167-S168. [PubMed: 17884562]

52. Alliance for a Healthier Generation. [Accessed February 7, 2011] Competitive beverage guidelines. Available at: http://www.healthiergeneration.org/companies.aspx?id=1376

53. Acton KJ, Burrows NR, Moore K, Querec L, Geiss LS, Engelgau MM. Trends in diabetes prevalence among American Indian and Alaska native children, adolescents, and young adults. Am J Public Health. 2002; 92(9):1485-1490. [PubMed: 12197981]

54. Livingstone MB, Robson PJ. Measurement of dietary intake in children. Proc Nutr Soc. 2000; 59(2):279-293. [PubMed: 10946797]

55. Yun S, Zhu BP, Black W, Brownson RC. A comparison of national estimates of obesity prevalence from the behavioral risk factor surveillance system and the National Health and Nutrition Examination Survey. Int J Obes (Lond). 2006; 30(1):164-170. [PubMed: 16231026] 


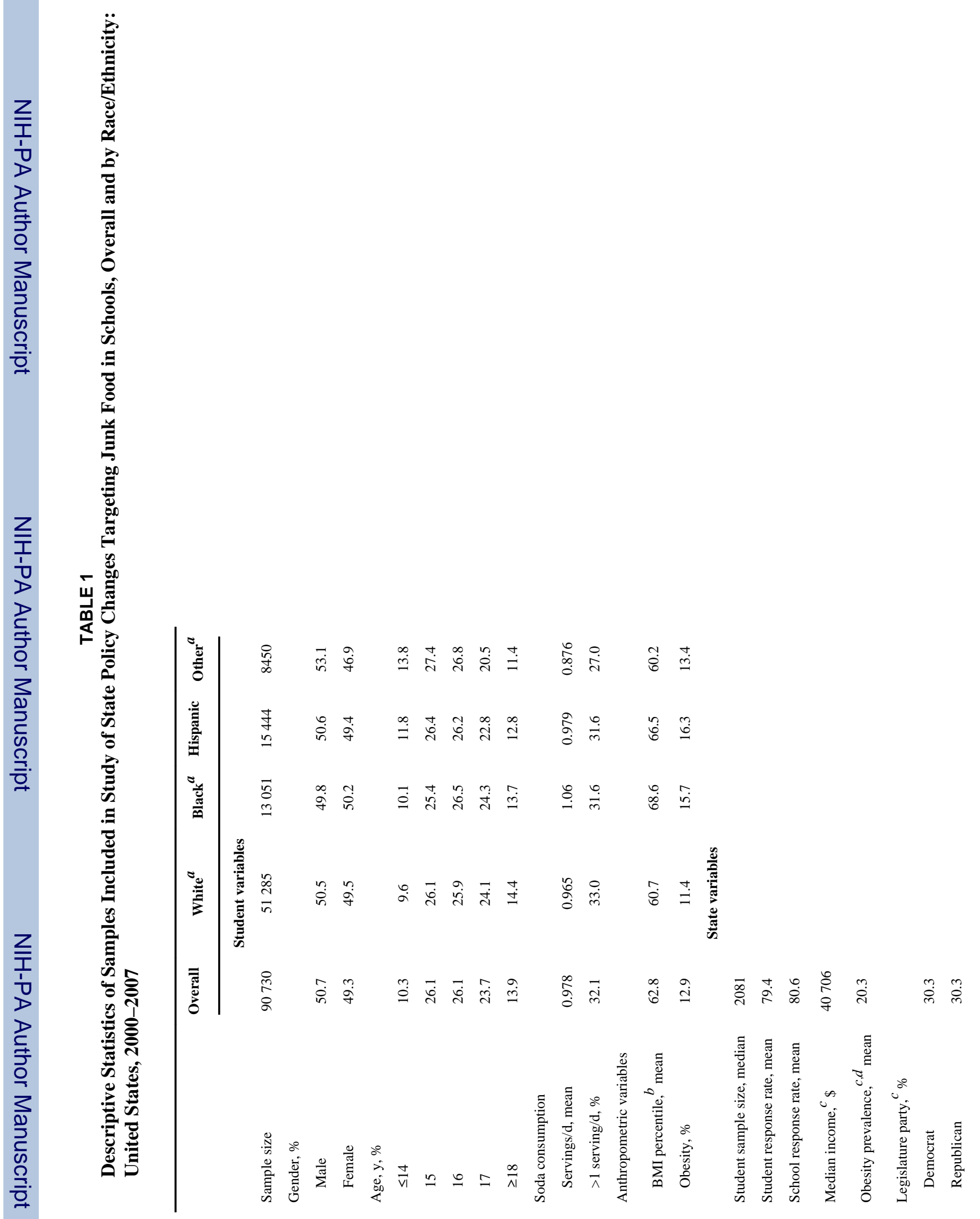




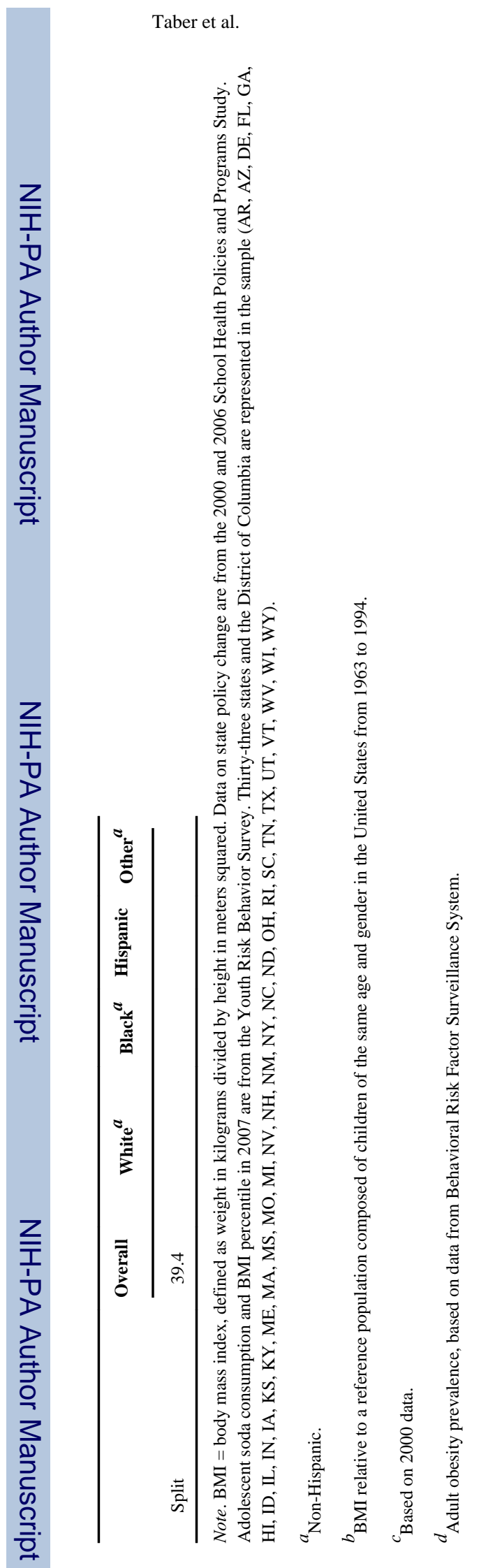

Am J Public Health. Author manuscript; available in PMC 2011 November 10. 


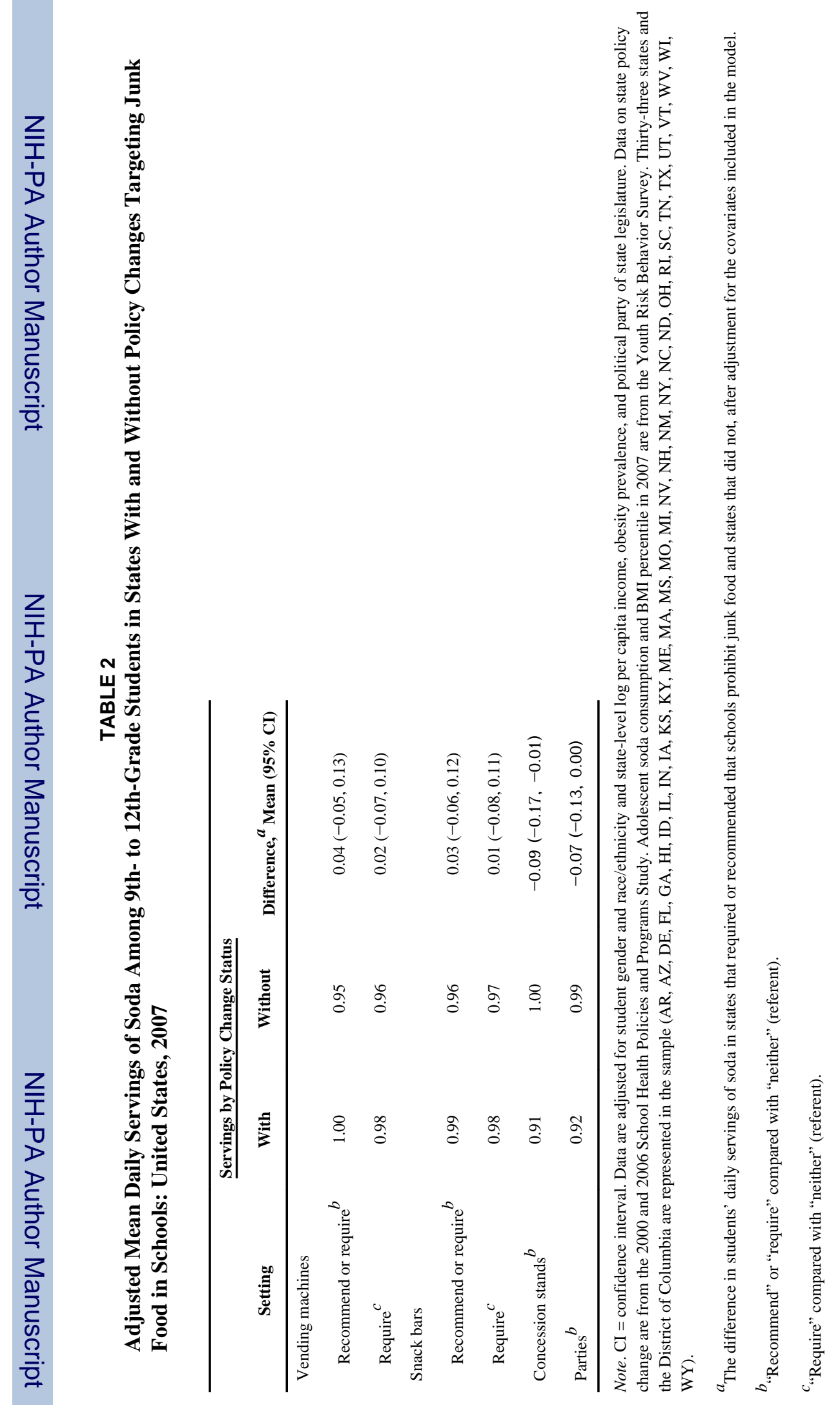




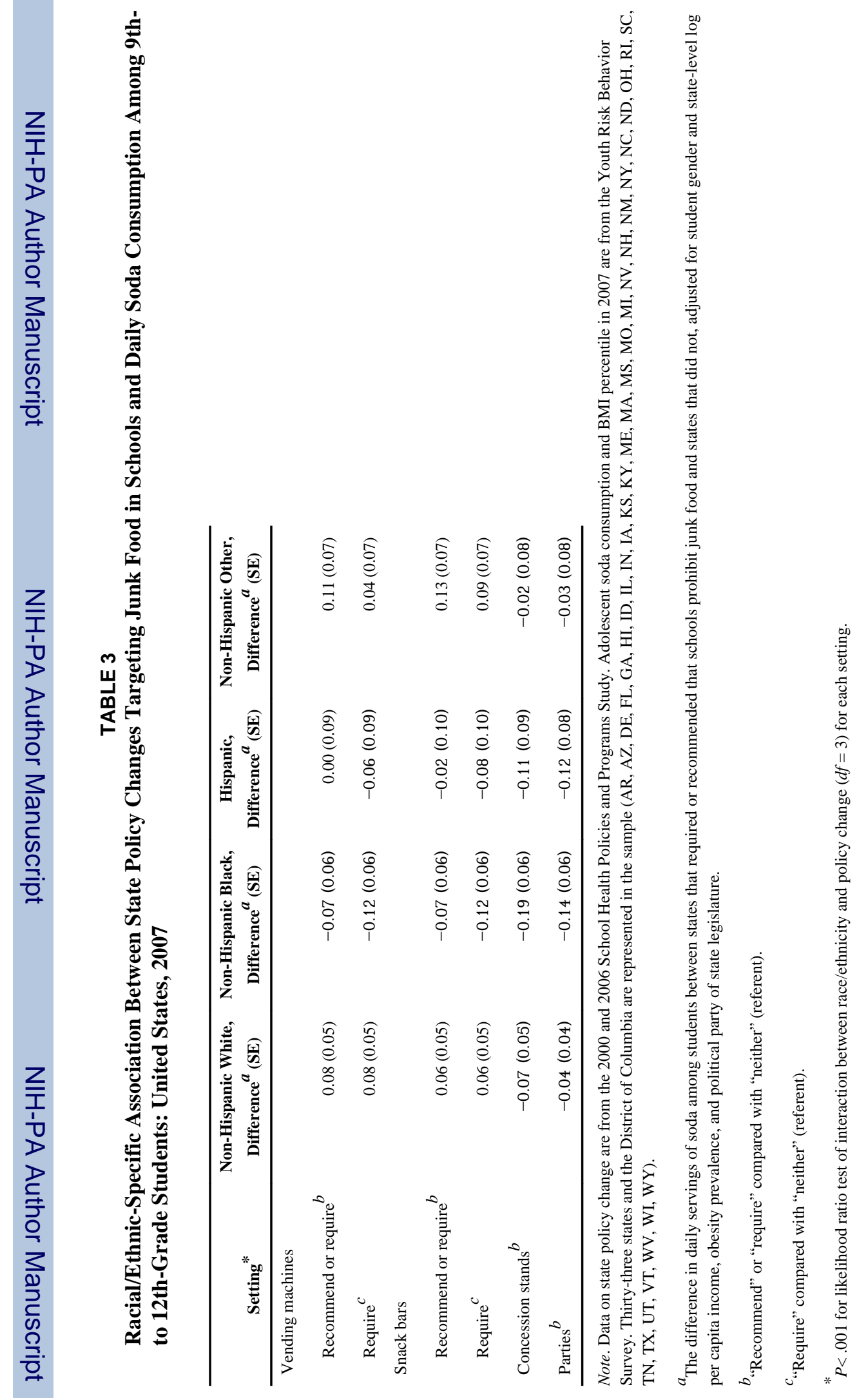




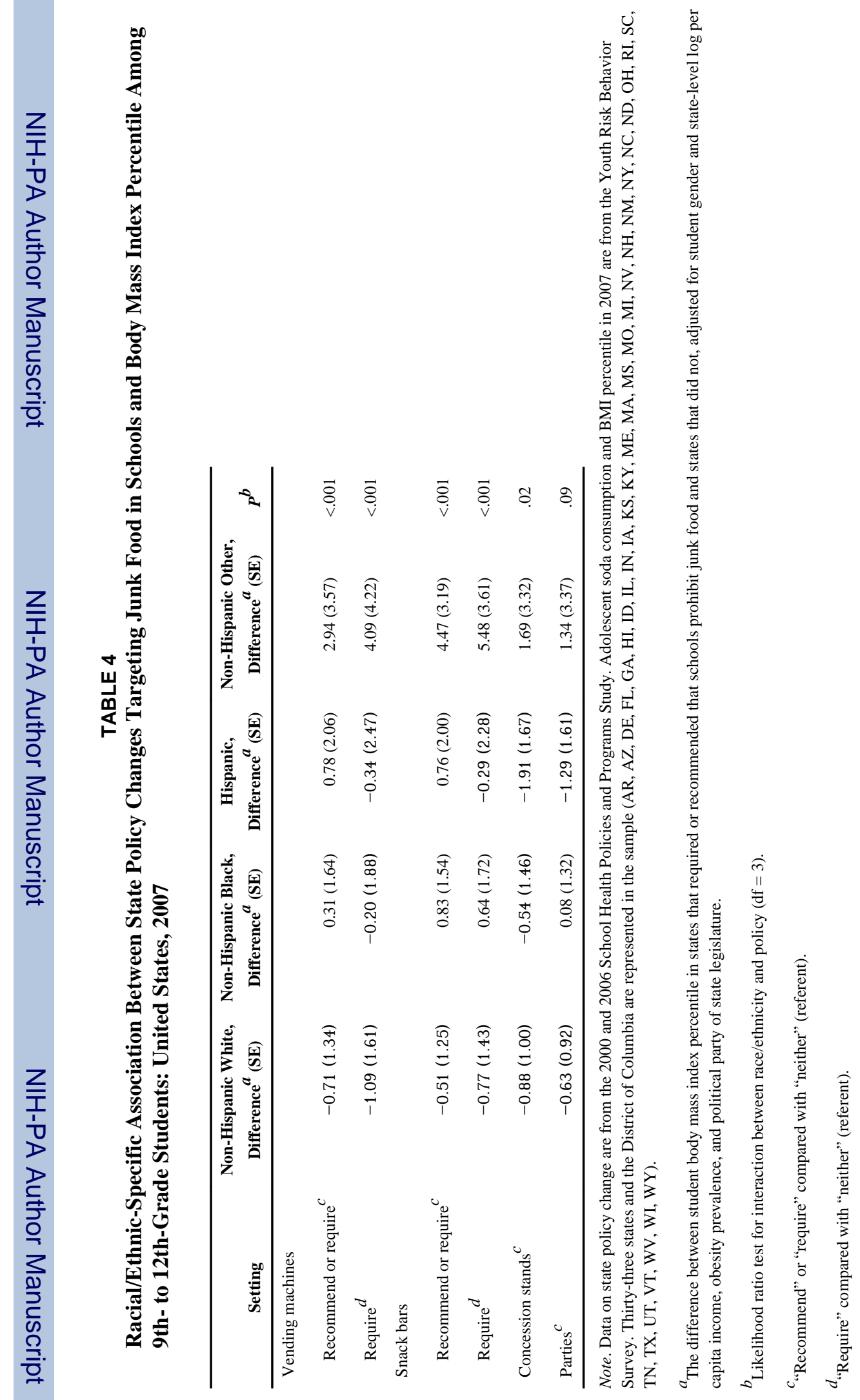

